\title{
Valor nutricional de alimentos alternativos para tambaqui (Colossoma macropomum)
}

\author{
Soares, K.J.A.; Ribeiro, F.B. ${ }^{@}$; Bomfim, M.A.D. e Marchão, R.S.
}

Centro de Ciências Agrárias e Ambientais. Universidade Federal do Maranhão (CCAA/UFMA). Chapadinha. MA. Brasil.

\section{PALAVRAS-CHAVE ADICIONAIS}

\section{Digestibilidade.}

\section{Energia.}

Nutriç̃ão de peixes.

Piscicultura.

Proteína.

\section{RESUMO}

O experimento foi conduzido com o objetivo de determinar a composição química e os coeficientes de digestibilidade aparente da matéria seca (CDAMS), proteína bruta (CDAPB), extrato etéreo (CDAEE) e da energia bruta (CDAEB) de alimentos alternativos para o tambaqui. No experimento foram utilizados 108 tambaquis com peso médio de 165,3 $\pm 15,6 \mathrm{~g}$, em seis tratamentos e três repetições, sendo seis peixes por parcela experimental. Foram confeccionadas seis rações experimentais, sendo uma ração referência, baseada de farelo de soja e milho, e, as demais contendo $70 \%$ da ração referência, e 30\% dos alimentos testados (farelo de arroz integral (FAl), farinha do feno da folha da leucena (FFL), farinha do feno da folha da mandioca (FFM), raspa da raiz integral da mandioca (RRIM) e a torta de babaçu (TB)). Para avaliar a digestibilidade aparente dos nutrientes, utilizou-se o método indireto de coleta de fezes por decantação e dióxido de titânio como indicador inerte adicionado à dieta em uma concentração de 0,1\%. Dentre os alimentos avaliados, a FFM, FFL e da TB contêm elevados teores de fibras, o que reduz os coeficientes de digestibilidade dos referidos alimentos. O FAI e a RRIM apresentam os maiores CDAMS, CDAPB, CDAEE e CDAEB, indicando que podem ser alimentos com potencial no uso em rações para tambaqui.

Nutritional value of alternative food for tambaqui (Colossoma macropomum)

\author{
ADDITIONAL KEYWORDS \\ Digestibility. \\ Energy. \\ Fish nutrition. \\ Pisciculture. \\ Protein. \\ INFORMATION \\ Cronología del artíiculo. \\ Recibido/Received: 27.05.2016 \\ Aceptado/Accepted: 07.10.2017 \\ On-line: 15.10 .2017 \\ Correspondencia a los autores/Contact e-mail: \\ felipebribeiro@yahoo.com
}

\section{SUMMARY}

\begin{abstract}
The experiment was conducted in order to determine the chemical composition and apparent digestibility coefficients $(A D C)$ of dry matter $(A D C D M)$, crude protein $(A D C C P)$, ether extract (ADCEE) and gross energy (ADCGE) of alternative foods for tambaqui. In the experiment were used 108 tambaquis with average weight of $165.3 \pm 15.6 \mathrm{~g}$, in six treatments and three replicates, being six fish per experimental plot. Six experimental rations were made, being a reference ration, based on soybean meal and corn, and the others containing $70 \%$ of the reference ration, and $30 \%$ of the foods tested (whole rice bran (WRB), hay meal of leucaena leaf (MLL), hay meal of cassava leaf (MCL), integral scrapings from cassava root (ISCR) and babassu meal (BM)). In order to evaluate the apparent digestibility of nutrients, the indirect method of collecting feces by decanting was used, using titanium dioxide as an inert indicator added to the diet in a concentration of $0.1 \%$. Among the evaluated foods, the MLL, MCL and BM containing high levels of fiber, which reduces the food digestibility coefficients. Among the evaluated foods, WRB and ISCR showed higher ADCDM, ADCCP, ADCEE and ADCGE values, indicating that they could be used in tambaqui rations.
\end{abstract}

\section{INTRODUÇÃO}

O aumento populacional mundial, a depleção nos estoques pesqueiros naturais e a busca por proteína de qualidade e saudável, acelerou o crescimento na demanda mundial por pescado. O Brasil dispõe de imenso potencial para a piscicultura em virtude de condições naturais muito favoráveis, por ser rico em recursos hídricos com muitas propriedades rurais de áreas inundáveis, ter espécies nativas com grande potencial para produção, ter clima propício, ter diversidade de espécies, além de ser grande produtor de grãos (Rocha et al., 2013).
Entre as espécies aquáticas criadas no Brasil, o tambaqui destaca-se como a espécie nativa mais cultivada representado 19,87\% da aquicultura Brasileira, com produção de 135,86 mil toneladas no ano de 2015 (IBGE, 2015).

O interesse crescente da produção de tambaqui é devido ao grande potencial para a criação, carne de excelente qualidade, rápido crescimento, resistência a baixos níveis de oxigênio dissolvido, hábito alimentar diversificado, rusticidade, adaptação ao confinamento e arraçoamento (Pereira Junior et al., 2013). 
A piscicultura tem conquistado grandes avanços na qualidade da produção, e na eficiência do manejo, visando sempre máxima produtividade, requerendo a utilização de dietas que atendam às exigências nutricionais por meio do uso adequado de rações balanceadas.

A formulação de rações para peixes é baseada principalmente em milho e farelo de soja, os quais, em função de grande variabilidade de preço, dependendo da oferta no decorrer do ano e da dificuldade de transporte para as regiões não produtoras desses alimentos, pode tornar muitas vezes a produção de peixes inviável (Santos et al., 2008). Assim, a busca constante de alimentos alternativos que possam substituir os alimentos tradicionalmente utilizados no país, de forma a reduzir custos e manter, ou até mesmo melhorar o desempenho dos animais, é um grande desafio para os nutricionistas (Pascoal et al., 2006a).

Para viabilizar a utilização de um alimento na formulação de rações, há a necessidade da determinação da composição química e da determinação dos coeficientes de digestibilidade da energia e de nutrientes. A determinação do coeficiente de digestibilidade é de grande importância, uma vez que expressa a quantidade de energia e/ou nutrientes digestíveis dos alimentos potencialmente disponíveis para a espécie. Como consequência, promove aumento na eficiência de utilização dos nutrientes, melhora a qualidade do pescado e minimiza a excreção de resíduos fecais e metabólicos (Pezzato et al., 2002).

Ainda são escassas as pesquisas que abordam a utilização de alimentos alternativos, principalmente da região Nordeste do Brasil, para o tambaqui. Também são insuficientes as informações acerca da composição química e da digestibilidade dos resíduos originados da agroindústria, sendo que muitos desses alimentos não convencionais são desprezados quanto ao seu uso (Santos et al., 2008).

O presente trabalho objetiva determinar a composição química e os coeficientes de digestibilidade aparente da matéria seca, proteína bruta, extrato etéreo e energia bruta do farelo de arroz integral, farinha do feno da folha da leucena, farinha do feno da folha da mandioca, raspa da raiz integral da mandioca e torta de babaçu para tambaqui na fase de crescimento.

\section{MATERIAL E MÉTODOS}

O experimento foi aprovado pela comissão de ética em experimentação animal com protocolo de $\mathrm{n}^{\mathrm{o}}$ : 23115.007034/2014-47 e conduzido no Laboratório de Nutrição e Alimentação de Organismos Aquáticos do Maranhão, no Centro de Ciências Agrárias e Ambientais da Universidade Federal do Maranhão, Chapadinha-MA, com duração de 14 dias. O método utilizado para avaliação da digestibilidade aparente foi o indireto de coletas de fezes utilizando $0,1 \%$ de dióxido de titânio $\left(\mathrm{TiO}_{2}\right)$ como indicador inerte.

A raspa da raiz integral da mandioca foi obtida das raízes, que depois de colhidas no campo, foram lavadas com água, picadas manualmente, espalhadas sobre uma lona plástica, e seca a sombra por cinco dias. Posteriormente, foi triturada em forrageira tipo martelo com peneira de $1 \mathrm{~mm}$.
As farinhas do feno da folha da leucena e do feno da folha da mandioca foram obtidas após a retirada manualmente das folhas dos galhos, sendo em seguida secas em estufa de circulação forçada por 24 horas a uma temperatura de $40^{\circ} \mathrm{C}$. Posteriormente, foram moídas em moinho tipo faca, com peneira de $1 \mathrm{~mm}$.

A torta do babaçu foi obtida após a extração do óleo por meio de prensagem das amêndoas do babaçu, já o farelo de arroz integral foi obtido após a brunição e polimento do grão de arroz sem casca.

Logo após o processamento dos alimentos, foi retirada uma amostra para realização das análises químicas, em seguida foram armazenados em sacos plásticos e congelados a $-18^{\circ} \mathrm{C}$ em freezer.

As seis rações experimentais foram confeccionadas a base de farelo de soja e milho (tabela I), sendo uma referência e as demais contendo $70 \%$ da ração referência e 30\% dos alimentos testados (farelo de arroz integral, farinha do feno da folha da leucena, farinha do feno da folha da mandioca, raspa da raiz integral da mandioca e a torta de babaçu). Posteriormente as rações experimentais foram peletizadas.

Os 108 tambaquis com peso médio de 165,3 \pm 15,6 g foram distribuídos em 18 gaiolas em formato cilíndrico (seis tratamentos com três repetições e seis peixes por parcela experimental). Cada gaiola ficava dentro de caixa de polietileno com volume de $1000 \mathrm{~L}$, dotadas de sistemas individuais de aeração, abastecimento e escoamento de água. A temperatura da agua foi monitorada duas vezes ao dia (08:00 h e 16:00 h). Os controles do $\mathrm{pH}$ e do teor de oxigênio dissolvido e da amônia na água foram aferidos a cada 3 dias, respectivamente, por intermédio de um potenciômetro, oxímetro e kit comercial para teste de amônia tóxica.

Durante o dia, os peixes receberam nas gaiolas as dietas testes fornecidas duas vezes pela manhã e duas vezes a tarde, até a saciedade aparente.

Para a coleta de fezes, as gaiolas com os peixes foram transferidas às 18:0 0h para os aquários de coleta (incubadoras em formato cônico confeccionados em fibra de vidro) com volume de $250 \mathrm{~L}$. Utilizou-se para a coleta de fezes um tubo (mamadeiras) acoplado no fundo dos aquários de coleta, onde se sedimentavam as excretas por decantação (método de Guelph modificado), de acordo com Abimorad e Carneiro (2004). Para evitar fermentação das fezes, as mamadeiras foram colocadas em caixas térmicas com gelo durante todo o período de coleta que ocorria em intervalos de duas horas, iniciando as 20:00 h e tendo como último horário de coleta as 06:00 h. Antes das gaiolas com os peixes serem devolvidos para as caixas de polietileno de $1000 \mathrm{~L}$, os tanques foram limpos, retirando restos de ração e fezes. Após cada coleta, as fezes foram colocadas em placa de petri, em seguida levada para estufa de circulação fechada, para secagem a $55^{\circ} \mathrm{C}$ durante 72 horas para fins de análises laboratoriais.

As análises químicas de matéria seca (MS), proteína bruta (PB), extrato etéreo (EE), matéria mineral (MM), fibra bruta (FB), fibra detergente neutra (FDN), fibra detergente acido (FDA) e energia bruta (EB) dos alimentos testados e das fezes, foram realizados no Laboratório de Nutrição Animal da Universidade Federal do Maranhão- 
Tabela I. Composição percentual e química da raçao referencia a base de farelo de soja e milho (Percentage composition chemistry of basal diet the basis of soybean meal and corn).

\begin{tabular}{lc}
\hline Alimentos & Ração referência \\
\hline Soja farelo 45\% & 54,55 \\
Milho grão & 34,87 \\
Óleo de soja & 5,21 \\
Fosfato bicalcio & 4,04 \\
Sal comum & 0,43 \\
Premix mineral e vitamínico ${ }^{1}$ & 0,50 \\
DL-metionina & 0,14 \\
L- treonina & 0,11 \\
Dióxido de titânio & 0,10 \\
BHT & 0,02 \\
Total & 100,00 \\
Composição calculada & \\
Proteína bruta & $28,00 \%$ \\
Energia digestível & $3,2 \mathrm{Mcal} / \mathrm{Kg}$ \\
Fósforo disponível & $0,88 \%$ \\
Cálcio & $1,88 \%$ \\
Sódio & $0,22 \%$ \\
Lisina total & $1,60 \%$ \\
Metionina + Cistina total & $0,96 \%$ \\
Metionina total & $0,55 \%$ \\
Treonina total & $1,20 \%$ \\
Triptofano total & $0,37 \%$ \\
\hline
\end{tabular}

${ }^{1}$ Composição do premix mineral e vitamínico: Vit. A, 1200000 UI; Vit. D3, 200000 Ul; Vit. E, 1200 mg; Vit. K3, 2400 mg; Vit. B1, 4800 mg; Vit. B2, 4800 mg; Vit. B6, 4800 mg; Vit. B12, 4800 mg; Vit. C, 48 g; ác. Fólico, 1200 mg; pantotenato de Ca, 12000 mg; Vit. C, 48000 mg; Biotina, 48 mg; Cloreto de colina, 108 g; Niacina, 24 000 mg; Fe, 50000 mg; Cu, 3000 mg; Mn, 20000 mg; Zn, 30000 mg; I, 100 mg; Co, 10 mg; Se, 100 mg.

UFMA, de acordo com metodologias descritas por Silva e Queiroz (2002). A energia bruta (EB) foi determinada em bomba calorimétrica modelo Cal2K. A digestibilidade aparente da matéria seca, proteína bruta, energia bruta e extrato etéreo da ração referência e das cinco rações contendo 30\% dos alimentos estudados foram calculados por meio da equação proposta por Nose (1960).

\section{$\operatorname{CDA}(\%)=100-\{100 \%$ indicador da dieta $\times \%$ nutriente nas fezes $\%$ indicador nas fezes \% nutriente na dieta}

As digestibilidades aparentes da MS, PB, EB e EE exclusivamente dos alimentos testados foram calculados de acordo com a metodologia de Pezzato et al. (2004).

$$
\mathrm{CDa}(\mathrm{alim})=\frac{\mathrm{CD}(\mathrm{rt})-\mathrm{b} \cdot \mathrm{CD}(\mathrm{rb})}{\mathrm{a}}
$$

Em que: $\mathrm{CDa}($ alim $)=$ coeficiente de digestibilidade aparente do alimento; $\mathrm{CD}(\mathrm{rt})=$ coeficiente de digestibilidade aparente da ração com o alimento teste; $\mathrm{CD}(\mathrm{rb})=$ coeficiente de digestibilidade aparente da ração basal; $\mathrm{b}=$ percentagem da ração basal; a= percentagem do alimento teste.

\section{RESULTADOS E DISCUSSÃO}

Os valores observados durante o período de temperatura foram de $27,6 \pm 0,5^{\circ} \mathrm{C}$ pela manhã e $28,1 \pm 0,3^{\circ} \mathrm{C}$ a tarde, $\mathrm{pH}$ de 6,96 $\pm 0,56$, oxigênio dissolvido de 8,87 \pm $0,5 \mathrm{mg} / \mathrm{L}$ e a amônia tóxica variou na faixa de 0,1 a 0,3 $\mathrm{mg} / \mathrm{L}$. Souza (2004) relata que os níveis recomentados de amônia tóxica são de até $1,0 \mathrm{mg} / \mathrm{L}$.

A proteína bruta do farelo de arroz integral de 15,12\% (tabela II), está entre os valores encontrados na literatura de $8,5 \%$ (Pezzato et al., 2002) a 15,66\% (Novoa, 2009), assim como o valor da matéria mineral de 6,75\%, com valores em estudos variando de 1,14\% (Pezzato et al., 2002) a $8,5 \%$ (Gonçalves e Carneiro, 2003).

A energia bruta de $4867,78 \mathrm{kcal} / \mathrm{kg}$ observada é semelhante ao descrito por Rostagno et al. (2011) de 4852,24 $\mathrm{kcal} / \mathrm{kg}$ e superior aos resultados expostos por Pezzato et al. (2002) de 3940,0 kcal $/ \mathrm{kg}$ com extrato etéreo de 1,1\% inferior ao encontrada no presente estudo de $12,37 \%$. A composição química do FAI depende de fatores associados à variedade genética do arroz, condições ambientais de cultivo, a constituição do grão ou processo de beneficiamento, como brunição e polimento, que afetam o conteúdo de carboidratos e fibra alimentar (Santos, 2006).

O FAI pode ser contaminado por falta de condições sanitárias de recolhimento ou contaminação desse farelo no processamento pelo endosperma que altera o teor de amido, ou com resíduos de casca que afeta o valor de fibras (Lacerda et al., 2010). Estes mesmos autores estudando diferentes variedades de FAI concluíram que a fibra alimentar presente no FAI é constituída basicamente por hemicelulose, com alta capacidade de retenção de àgua e por lignina, que é indigestível. Devido a ausência de padronização no processamento, a composição química do farelo de arroz integral pode apresentar grande variabilidade de resultados (Vieira et al., 2007).

O valor de $25,48 \%$ de proteína bruta do FFL, corresponde aos resultados médios obtidos na literatura, entre 19,53\% (Campeche et al., 2011) a 32,6\% (Pezzato et al., 2004). O teor de extrato etéreo, $3,86 \%$, foi semelhante ao encontrado por Pereira Junior et al. (2013) de 3,5\%. O teor de energia bruta de 5348,24 kcal/ $\mathrm{kg}$ da FFL apresentou um valor elevado comparado a outros trabalhos como o de Campeche et al. (2011) com 3340,0 kcal/kg e Araújo et al. (2012), que descreveram $4856,89 \mathrm{kcal} / \mathrm{kg}$, com extrato etéreo de $3,2 \%$, inferior ao encontrado no presente estudo.

O valor nutritivo da folha da leucena tende a ser influenciado pela adequada frequência da desfolha, propiciando uma preponderância de folhas mais jovens com maior valor nutritivo em comparação às folhagens mais maduras. A amplitude das variações de proteína e fibra é determinada pelas condições edafoclimáticas que a planta está sujeita ou com a idade do material vegetativo (Pereira et al., 1995).

A composição química da FFM quanto aos valores de MS (92,03\%), MM (6,41\%), PB (20,97\%), FDN (38,07\%) e FDA $(21,26 \%)$, apresentou resultados semelhantes aos encontrados por Braga et al. (2010), que verificaram teo- 
Tabela II. Valores da MS (matéria seca), PB (proteína bruta), EE (Extrato etéreo), FB (fibra bruta), FDN (fibra em detergente neutro), FDA (fibra em detergente ácido), MM (matéria mineral) e EB (energia bruta), do farelo de arroz integral (FAI), farinha do feno da folha da leucena (FFL), farinha do feno da folha da mandioca (FFM), raspa da raiz integral da mandioca (RRIM) e da torta de babaçu (TB, expressa na matéria natural (Values of DM (dry matter), CP (crude protein), EE (ether extract), FB (crude fiber), NDF (neutral detergent fiber), FDA (acid detergent fiber), MM (mineral matter) and EB (gross energy) of whole rice bran (WRB), hay meal of leucaena leaf (MLL), hay meal of cassava leaf (MCL), integral scrapings from cassava root (ISCR) and babassu meal (BM) expressed in dry matter).

\begin{tabular}{lcccccccc}
\hline Alimento & MS $\%$ & PB $\%$ & EE $\%$ & FB $\%$ & FDN \% & FDA \% & MM \% & EB Kcal / Kg \\
\hline FAI & 91,32 & 15,12 & 12,37 & 3,77 & 22,39 & 7,56 & 6,75 & 4867,78 \\
FFL & 90,12 & 25,48 & 3,86 & 9,66 & 25,23 & 19,08 & 6,62 & 5348,24 \\
FFM & 92,03 & 20,97 & 5,35 & 10,92 & 38,07 & 21,26 & 6,41 & 5194,84 \\
RRIM & 91,73 & 2,03 & 0,86 & 1,85 & 17,97 & 7,07 & 4,11 & 3696,00 \\
TB & 92,37 & 20,18 & 7,58 & 19,68 & 69,70 & 37,43 & 5,27 & 4791,39 \\
\hline
\end{tabular}

res de $92,74 \%$ MS, 6,5\% MM, 21,87\% PB, 38,38\% FDN e $25,29 \%$ FDA. De acordo com Correia et al. (2005), as folhas de mandioca apresentam alta variação nos valores de proteína de 14,7\% a 40\%. A energia bruta da FFM do presente estudo, apresentou valores de 5194,84 kcal/kg e de extrato etéreo de $5,35 \%$, superiores aos relatados por Araújo et al. (2012) com 4824,9 kcal/kg de EB e 4,97\% EE.

A qualidade nutricional da folha de mandioca depende de vários fatores, como solo de cultivo, idade da planta, variedade genética, tempo de utilização das folhas depois de colhidas, que interferem na redução de níveis tóxicos de fatores antinutricionais, além da proporção entre folhas e talos (Gil e Buitrago, 2002). Uma maior proporção de folhas melhora a qualidade nutricional, pois os níveis de proteína e fibra nas folhas são, respectivamente na matéria seca em torno de $25 \%$ e $9 \%$, enquanto que nos talos e pecíolos são de $11 \%$ e $25 \%$ (Hisano et al., 2008).

A energia bruta observada da raspa da raiz integral da mandioca de $3696,00 \mathrm{kcal} / \mathrm{kg}$ foi inferior ao valor relatado por Carvalho et al. (2012) de 3924,0 Kcal/kg, sendo atribuído essa variação de resultados ao elevado teor de extrato etéreo $(3,05 \%)$ encontrado pelos autores comparação a apenas 0,86 EE encontrado no presente estudo (0,86\%). Boscolo et al. (2002), com teores de extrato etéreo semelhante de $0,94 \%$, descreveram energia bruta de $3588,72 \mathrm{Kcal} / \mathrm{kg}$ para farinha de varredura de mandioca análoga ao presente estudo. Segundo Hisano et al. (2008), a composição química da raiz da mandioca por ser rica em amido, açúcares solúveis e carboidratos de rápida digestibilidade, proporcionam uma energia bruta elevada, sendo que outra característica que favorece o valor de energia bruta da raiz integral da mandioca é possuir baixos teores de fibra na sua composição. O valor da fibra bruta encontrado no presente estudo foi de 1,85\%, 17,97\% FDN e 7,07\% FDA.

A cultura da mandioca apresenta uma ampla diversidade genética, resultado da facilidade de polinização cruzada da espécie, alta heterozigozidade e da deiscência abrupta dos frutos, existindo muitas diferenças de valores de composição química dentre as variedades utilizadas na nutrição animal (Hisano et al., 2008). Porém quando expressa com base na MS, o teor de PB geralmente não ultrapassa $3 \%$, sendo um alimento com limitados teores proteicos. $\mathrm{O}$ valor de $\mathrm{PB}$ de $2,03 \%$ verificado na raiz integral da mandioca apresentou resultado similar com outros trabalhos encontrados na literatura, com teores variando de $1,11 \%$ (Sousa et al., 2012) a 3,21\% (Carvalho et al., 2012).

A torta de babaçu avaliada apresentou 20,18\% PB na MS, valor próximo aos encontrados na literatura, com 19,72\% (Gasparini et al., 2015) e 21,35\% (Santos Neta et al., 2011). Os subprodutos possuem oscilações de teores de PB e FB devido ao tipo e o tempo de processamento, bem como as condições de armazenamento, que afetam a composição química do produto final (Pascoal et al., 2006b)

A fração fibrosa da torta de babaçu foi elevada, com 69,68\% DN e 37,43\% FDA, apresentando variação em relação a resultados obtidos em estudos com o mesmo alimento, tendo em vista os valores encontrados por Gasparini et al. (2015), com 75,57\% FDN e 45,97\% FDA; e por Silva et al. (2008) 66,21\% FDN e 34,22\% FDA. De acordo com Pascoal et al. (2006b), a contaminação da torta de babaçu no processamento por cascas e pericarpo, altamente lignificadas, proporciona alterações nos teores da fração fibrosa e no potencial de digestibilidade da torta de babaçu.

O conteúdo da matéria mineral, energia bruta e do extrato etéreo da torta de babaçu no presente estudo foi de $5,24 \%$, 4791,39 Kcal $/ \mathrm{kg}$ e 7,58\% respectivamente, valor semelhante ao encontrado por Santos Neta et al. (2011) de 5,30\% MM, 4847,0 Kcal/kg EB e 7,03\% EE. Para a energia bruta há na literatura valores variando entre $3828 \mathrm{kcal} /$ $\mathrm{kg}$ e $5056 \mathrm{kcal} / \mathrm{kg}$, conforme revisão apresentada por Siqueira et al. (2011).

Os coeficientes de digestibilidade aparente da matéria seca (CDAMS), proteína bruta (CDAPB), extrato etéreo (CDAEE) e energia bruta (CDAEB) do farelo de arroz integral (FAI) foram de 71,34\%, 80,97\%, 72,93\% e $78,54 \%$, respectivamente (tabela III). Estes valores são semelhantes aos descritos por Gonçalves et al. (2004), que trabalhando com tilápia do Nilo (Oreochromis niloticus) com peso médio de $100 \mathrm{~g}$, observaram valores de 77,48\% CDAPB e 77,78\% CDAEB.

O potencial de assimilação de nutrientes da dieta é determinado pelas características do trato digestório dos peixes e da disponibilidade de enzimas adequadas presentes ao longo do canal alimentar (Moraes e Almeida, 2014).

A proximidade dos coeficientes de digestibilidade aparente observados entre as duas espécies pode ser 
atribuída a hábitos alimentares e condições nutricionais similares. A tilápia, assim como o tambaqui, são espécies onívoras com eficiência semelhante de habilidade de assimilação do alimento. Os peixes onívoros apresentam características especificas de perfil enzimático do canal alimentar, além de intestinos longos, permitindo que o alimento ingerido permaneça mais tempo em contato com as enzimas digestivas, otimizando a capacidade absortiva de utilizar vários componentes da dieta (Gonçalves et al., 2004; Moraes e Almeida, 2014).

Por outro lado, Abimorad e Carneiro (2004), trabalhando com pacu com peso médio de $310 \mathrm{~g}$, relataram valores superiores aos encontrados neste estudo para FAI, de $80,82 \%$ CDAPB e de $92,73 \%$ CDAEB. Estas diferenças podem ser atribuídas pelo fato dos referidos autores terem utilizados peixes maiores, que possuem maior capacidade de aproveitamento dos nutrientes e do alimento em relação a peixes menores.

Durante o processo de desenvolvimento dos peixes podem ser observadas mudanças na estrutura e na anatomia do tubo digestório em peixes onívoros. Devido a adaptação ao hábito alimentar diversificado, maior será a variação do comprimento do intestino, afetando na capacidade de digestão e absorção de nutrientes (Bomfim e Lanna, 2004).

Outros estudos realizados com FAI, como de Teixeira et al. (2010), com surubim (Pseudoplatystoma fasciatum), que encontraram valores de 59,67\% CDAMS e de 66,41\% CDAEB e Gonçalves e Carneiro (2003), com pintado (Pseudoplatystoma coruscans), que encontraram valores de $44,21 \%$ CDAPB e de 51,84\%. CDAEB. Todos os resultados obtidos pelos autores foram inferiores aos encontrados no presente estudo. As referidas espécies possuem hábito alimentar carnívoro (surubim e pintado), que diferem dos peixes de habito alimentar onívoro (tambaqui) na sua anatomia do trato intestinal, na habilidade e capacidade absortiva de nutrientes, que dependem da disponibilidade de enzimas presentes no sistema digestório.

Em peixes carnívoros, a secreção da amilase se restringe apenas ao pâncreas, no entanto a digestão de lipídios

\begin{tabular}{|c|c|c|c|c|}
\hline \multicolumn{5}{|c|}{$\begin{array}{l}\text { Tabela III. Coeficiente de digestibilidade aparente } \\
\text { da matéria seca (CDAMS), proteína bruta (CDAPB), } \\
\text { extrato etéreo (CDAEE), energia bruta (CDAEB) do } \\
\text { farelo de arroz integral (FAI), farinha do feno da } \\
\text { folha da leucena (FFL), farinha do feno da folha da } \\
\text { mandioca (FFM), raspa da raiz integral da mandio- } \\
\text { ca (RRIM) e da torta de babaçu (TB) para tambaqui } \\
\text { na fase de crescimento, com respectivos desvios- } \\
\text { padrões (Apparent digestibility of dry matter (ADCDM), crude } \\
\text { protein (ADCCP), ether extract (ADCEE), gross energy (ADCGE) } \\
\text { of rice bran (FAI) the whole rice bran (WRB), hay meal of leu- } \\
\text { caena leaf (MLL), hay meal of cassava leaf (MCL), integral scrap- } \\
\text { ings from cassava root (ISCR) and babassu meal (BM), with their } \\
\text { standard deviations). }\end{array}$} \\
\hline & CDAMS $\%$ & CDAPB $\%$ & CDAEE \% & \\
\hline & $71,34 \pm 2,65$ & $80,97 \pm 3,14$ & $72,93 \pm 2,81$ & 78,5 \\
\hline & & $74,77 \pm 2,79$ & $51,49 \pm 1,09$ & \\
\hline & 49,4 & $36,59 \pm 1,46$ & $53,80 \pm 2,15$ & \\
\hline & 88,52 & $88,69 \pm 3,55$ & $81,73 \pm 3,27$ & $89,09 \pm 3,66$ \\
\hline & $38,29 \pm 1,43$ & $29,16 \pm 1,17$ & $37,60 \pm 1,54$ & $25,68 \pm 1,12$ \\
\hline
\end{tabular}

ocorre em todo o canal do trato digestório, além de possui maiores atividades proteolíticas comparadas aos peixes onívoros. Enquanto que a síntese da amilase em espécies onívoras ocorre no pâncreas e em toda a mucosa intestinal, no qual a maior concentração dessa enzima permite melhor aproveitamento de carboidratos presentes em alimentos de origem vegetal (Gonçalves et al., 2012).

A farinha do feno da folha da leucena apresentou 57,08\% CDAMS, 74,77\% CDAPB, 51,49\% CDAEE e 29,91\% CDAEB. Dentre estudos de digestibilidade com feno da folha de leucena, Campeche et al. (2011), trabalhando com tilápia do Nilo, relataram valores próximos aos observados no presente estudo: 59,15\% CDAMS, $87,18 \%$ CDAPB e $28,83 \%$ CDAEB. A baixa digestibilidade da energia bruta pode estar relacionada aos altos teores de fibra encontrados, que foram de 25,23\% FDN e 19,08\% FDA, comprometendo a digestão e absorção de nutrientes, bem como influenciando negativamente $\mathrm{o}$ aproveitamento da energia.

A fração fibrosa não pode ser digerida por enzimas endógenas, afetando a digestibilidade e o tempo de permanência no trato digestivo. As fibras insolúveis aumentam a velocidade de passagem do bolo alimentar e reduz o tempo de digestão dos nutrientes, ao contrário de fibras solúveis, que diminuem o tempo de passagem do bolo alimentar devido a sua capacidade de se ligar a água formando um gel viscoso (Santos Jr. et al., 2004), o que diminui a taxa de difusão de substratos e enzimas digestivas no trato digestório levando ao comprometimento da digestão e absorção de nutrientes (Choct et al., 2004).

Além dos teores de fibra, outro componente que tem uma relação direta com os valores de digestibilidade de energia do alimento é o extrato etéreo (EE), visto que altos teores refletem em maiores coeficientes de digestibilidade. Pezzato et al. (2004) em trabalho realizado com digestibilidade da folha da leucena para tilápia do Nilo, encontraram 6,8\% EE e 63,53\%, CDAEB, divergindo do valor encontrado no presente estudo, com valor de EE inferior de 3,86\% e 29,91\% CDAEB, sugerindo que maiores teores de EE correspondem a maiores valores energéticos digestíveis. Dentre os combustíveis metabólicos lipídios, proteína e carboidratos, que podem ser utilizados para a obtenção de energia, os lipídios são os que apresentam maior valor calórico com 9,4 cal/g EB, em comparação a carboidratos $(4,15 \mathrm{cal} / \mathrm{g}$ EB) e proteínas $(5,65 \mathrm{cal} / \mathrm{g}$ EB) (Silva et al., 2014).

Os CDAMS, CDAPB, CDAEE e CDAEB da folha da mandioca avaliada com 38,07\% FDN e $21,26 \%$, FDA foram de $49,43 \%, 36,59 \%, 53,80 \%$ e $31,97 \%$, respectivamente. Braga et al. (2010), utilizando feno de folhas de mandioca com teores de fibra de 38,38\% FDN e 25,29\% FDA obtiveram resultados similares de CDAMS (50,22\%) e CDAEB $(29,29 \%)$.

Carvalho et al. (2012), estudando o valor nutritivo da folha de mandioca para tilápia do Nilo, encontraram valores de $81,22 \%$ CDAMS, 73,37\% CDAPB e 64,7\% CDAEB. Estes resultados diferem de outros descritos na literatura com a mesma espécie (Braga et al., 2010; Araújo et al., 2012), assim como dos valores encontrados no presente estudo. Os maiores valores de digestibilidade observado por Carvalho et al. (2012) podem ser atribuídos ao teor de extrato etéreo de $13,05 \%$, superior ao presente 
trabalho $(5,35 \%)$ e aos outros trabalhos relatados acima (4,97\% e 6,7\%, respectivamente).

Além do teor de extrato etéreo, o processo de extrusão utilizado por Carvalho et al. (2012) para a fabricação das dietas experimentais é outro fator diferenciado que interfere nos resultados elevados de digestibilidade descrito no trabalho. Durante o processo de extrusão a alta temperatura e pressão causam modificações químicas nos alimentos, provocando maior exposição dos nutrientes contidos nas células vegetais, melhorando a digestibilidade da proteína, além de redução de fatores antinutricionais, em relação aos alimentos ou rações não extrusadas (Carvalho et al., 2012).

Dentre os alimentos testados no presente estudo, a torta de babaçu apresentou os menores valores de digestibilidade aparente para MS, PB, EE e EB, ficando próximo aos valores observados na folha da mandioca, com valores de 38,29\% CDAMS, 29,16\% CDAPB , 37,90\% CDAEE e 25,68\% CDAEB . Não existe na literatura trabalhos de digestibilidade da torta do babaçu para peixes, o que inviabilizou comparações.

Os teores de fibra da torta de babaçu foram elevados, com 69,7 \% de FDN e 37,43\% de FDA. As fibras alimentares afetam a digestão e absorção de nutrientes e, possivelmente, a sua relação negativa com a digestibilidade de nutrientes na torta de babaçu, decorre principalmente da correlação com a fibra insolúvel, devido ao aumento da taxa de passagem no trato digestório, atuando como diluidor de nutrientes. A FDA é a fração fibrosa que contém a maior parte de fibras insolúveis, sendo que no caso da torta de babaçu, apresenta elevado teores de lignina, devido a contaminação por cascas e pericarpo altamente lignificados (Silva et al., 2008).

A torta de babaçu apresentou 32,27\% de hemicelulose, teor elevado se comparado a alimentos fibrosos como farelo de trigo com 26,46\% (Rostagno et al., 2011). Segundo Brito et al. (2008), a fibra solúvel é composta principalmente pela hemicelulose, que é descrita como heteropolissacarídeos de estrutura complexa e heterogênea, mas com um grau de polimerização inferior ao da celulose. Devido as suas propriedades de adsorver água e formar um gel viscoso, dificultam o contato enzima-substrato e, consequentemente, a absorção de nutrientes como proteínas, gorduras e amido, que tornam-se menos acessíveis às enzimas endógenas, levando ao comprometimento da digestão e da absorção de nutrientes (Fracalossi et al., 2012).

Os coeficientes de digestibilidade encontrados para raspa da raiz integral da mandioca foram superiores aos verificados para os outros alimentos avaliados no presente estudo com CDAMS, CDAPB, CDAEE e CDAEB de $88,52 \%, 88,69 \%$, $81,73 \%$ e $89,09 \%$, respectivamente. Estes valores são similares aos encontrados por Carvalho et al. (2012), trabalhando com tilápia do Nilo, com 91,44\% CDAMS, 91,47\% CDAPB e 92,2\% CDAEB , onde a pequena variação pode ser atribuído ao valor de extrato etéreo observado de 3,05\%, superior ao encontrado nesse trabalho $(0,86 \%)$, refletindo em maiores coeficientes de digestibilidade de energia e proteína.

Obstante aos resultados expostos, Novoa (2009) estudando valores de digestibilidade da raiz da mandioca para tilápias vermelhas com peso médio de 209 g, obser- varam valores elevados se comparados à outros estudos, com 97,51\% CDAPB e 93,14\% CDAEB, provavelmente devido ao tamanho do peixe, que por ser maior, possui trato digestório mais desenvolvido.

A raiz integral da mandioca possui elevados teores de carboidratos solúveis digestíveis e baixos teores de fibras, constituída por amido de alta digestibilidade, por possuir arranjo linear (amilose) inferior a arranjos ramificados (amilopectina), sendo que a digestibilidade do amido é inversamente proporcional ao seu conteúdo de amilose (Novoa, 2009; Pereira Junior et al., 2013). Dessa forma, a combinação da elevada digestibilidade do amido da mandioca com a amplitude da atividade da amilase em todo o trato digestório e nos cecos pilóricos do tambaqui, otimizam a digestibilidade de nutrientes da raiz da mandioca (Lanna et al., 2014).

\section{CONCLUSÕES}

A farinha do feno da folha da mandioca, farinha do feno da folha da leucena e da torta de babaçu contêm elevados teores de fibras, o que reduz os coeficientes de digestibilidade destes alimentos.

O farelo de arroz integral e a raspa da raiz integral da mandioca apresentam os maiores CDAMS, CDAPB, CDAEE e CDAEB, indicando que podem ser alimentos com potencial para uso em rações para tambaqui na fase de crescimento.

\section{AGRADECIMENTOS}

À Financiadora de Estudos e Projetos - FINEP, pelo apoio financeiro.

\section{BIBLIOGRAFIA}

Abimorad, E.G. e Carneiro, D.J. 2004. Métodos de coleta de fezes e determinação dos coeficientes de digestibilidade da fração protéica e da energia de alimentos para o pacu, Piaractus mesopotamicus (Holmberg, 1887). Rev Bras Zootecn, 33: 1101-1109.

Araújo, J.R.; Santos, L.D.; Silva, L.C.R.; Santos, O.O. e Meurer, F. 2012. Digestibilidade aparente de ingredientes do Semi-Árido Nordestino para tilápia do Nilo. Cienc Rural, 42: 900-903.

Bomfim, M.A.D. e Lanna, E.A.T. 2004. Fatores que afetam os coeficientes de digestibilidade nos alimentos para peixes. Rev Eletr Nutritime, 1: 20-30.

Boscolo, W.R.; Hayashi, C. e Meurer, F. 2002. Digestibilidade aparente da energia enutrientes de alimentos convencionais ealternativos para a tilápia do Nilo (Oreochromis niloticus, L.). Rev Bras Zootecn, 13: 539-545.

Braga, L.G.T.; Rodrigues, F.L.; Azevedo, R.V.; Carvalho, J.S.O. e Ramos, A.P.S. 2010. Digestibilidade aparente da energia e nutrientes de coprodutos agroindustriais para tilápia do Nilo. Rev Bras Saúde Prod Anim, 11: 1127-1136.

Campeche, D.F.B.; Moraes, S.A.; Sousa, V.T.L.S.N.; Oliveira, S.T.L.; Souza, M.G. e Paulino, R.V. 2011. Composição bromatológica e digestibilidade aparente de alimentos encontrados na região semiárida brasileira para arraçoamento de tilápia rosa em cultivos. Cienc Rural, 41: 343-348

Carvalho, P.L.P.F.; Silva, R.L.; Botelho, R.M.; Damasceno, F.M.; Rocha, M.K.H.R. e Pezzato, L.E. 2012. Valor nutritivo da raiz e folhas da mandioca para a tilápia do Nilo. Bol Inst Pesca, 38: $61-69$

Choct, M.; Kocher, A.; Waters, D.L.E.; Pettersson, D. and Ross, G. 2004. A comparison of three xylanases on the nutritive value of two wheats for broiler chickens. Br J Nutr, 92: 53-61.

Correia, A.D.; Farias, A.R.N. e Mattos, P.L.P. 2005. Utilização da mandioca e de seus produtos na alimentação humana. In: Sousa, 
L.S.; Farias, A.R.N.; Mattos, P.L.P.; Fududa, W.M.G. (Eds). Processamento e utilização da mandioca. Embrapa Mandioca e Fruticultura tropical. Cruz das Almas. Brasil. pp. 223-298.

Fracalossi, D.M.; Rodrigues, A.P.O. e Rosa, M.C.G. 2012. Carboidratos e fibras. In: Fracalossi, D.M.; Cyrino, J.E.P (orgs.). Nutrição e alimentação de espécies de interesse para a aquicultura brasileira. Nutriaqua. Florianópolis. 375 pp.

Gasparini, S.P.; Ribeiro, F.B.; Siqueira, J.C.; Bomfim, M.A.D. e Nascimento, D.C.N. 2015. Avaliação nutricional da torta de babaçu para frangos de crescimento lento em diferentes idades. Rev Caatinga. 28: 126-134.

Gil, L. y Buitrago A., J.A. 2002. La yuca en la alimentación animal. In: Ospina, B.; Ceballos, H. (Comp.). La yuca en el tercer milenio: sistemas modernos de producción, procesamiento, utilización y comercialización. CIAT. Cali. pp. 527-568.

Gonçalves, E.G. e Carneiro, D.J. 2003. Coeficientes de digestibilidade aparente da proteína eenergia de alguns ingredientes utilizados em dietas para o pintado (Pseudoplatystoma coruscans). Rev Bras Zootecn, 32: 779-786.

Gonçalves, G.S.; Pezzato, L.E.; Barros, M.M.; Hisano, H.; Freire, E.S. e Ferrari. J.E.C. 2004. Digestibilidade aparente e suplementação de fitase em alimentos vegetais para tilápia do Nilo. Acta Sci Anim Sci, 26: 313-321.

Gonçalves, L.U.; Rodrigues, A.P.O.; Moro, G.V.; Ferreira, E.C. e Cyrino, J.E.P. 2012. Morfologia e fisiologia do sistema digestório de peixes. In: Fracalossi, D.M.; Cyrino, J.E.P (orgs.). Nutrição e alimentação de espécies de interesse para a aquicultura brasileira. Nutriaqua. Florianópolis. $375 \mathrm{pp}$. Hisano, H.; Maruayama, M.R.I.; Shikawa, M.M. e Melhorança, A.L. 2008. Potencial da utilização da mandioca na alimentação de peixes. Embrapa/ Agropecuária Oeste. Cuiabá. 29 pp.

IBGE - Instituto Brasileiro de Geografia e Estatística. 2015. Produção da Pecuária Municipal.

Lacerda, D.B.C.L.; Júnior, M.S.S.; Bassinello P.Z.; Castro, M.V.L. e Silva-lobo, V.L. 2010. Qualidade de farelo de arroz cru, extrusado e parboilizado, Pesq Agropec Trop, 40: 521-530.

Lanna, E.A.T.; Vianna, R.A. e Jorge, T.F.B. 2014. Anatomia e fisiologia do trato gastrointestinal de peixes. In: Nutrição de não ruminantes. Sakomura, N.K. FUNEP. Jaboticabal. PP. 268-294.

Moraes, G. e Almeida, L.C. 2014. Nutrição e aspectos funcionais da digestão de peixes. In: Baldisseroto, B.; Cyrino, J.E.P.; Urbinati, E.C. Biologia e fisiologia de peixes neotropicais de agua doce. FUNEP, UNESP. Jaboticabal, pp. 233-252.

Nose, T. 1960. On the effective value of freshwater green algae, Chllorella ellipoidea, as nutritive source to gold fish. Bulletin Fresh Fish Res, 10: 1-10.

Novoa, D.M.T. 2009. Valor energético e digestibilidade da proteína em alimentos para tilápia vermelha. (Dissertação de Mestrado). Universidade Estadual do Norte Fluminense Darcy Ribeiro. 52 pp.

Pascoal, L.A.F; Miranda, E.C. e Silva Filho, F.P. 2006a. O uso de ingredientes alternativos em dietas para peixes. Rev Eletr Nutritime, 3: 284-298.

Pascoal, L.A.F.; Bezerra, A.P.A. e Gonçalves, J.S. 2006b. Farelo de babaçu: valor nutritivo e utilização na alimentação animal. Rev Eletr Nutritime, 3: 339-345

Pereira, A.F.; Alcantara, P.B. e Braum, G.C.B.E.S. 1995. Variação da composição química de Leucaena leucocephala (Lam) de wit sujeita a diferentes intensidades de desfolha. Bol Indústr Anim, 52: 127-132.

Pereira Junior, G. P.; Filho, M. P; Roubach, R.; Barbosa, P.S. e Shimoda, E. 2013. Farinha de folha de leucena (Leucaena leucocephala Lam.) como fonte de proteína para juvenis de tambaqui (Colossoma macropomum CUVIER, 1818). Acta Amaz, 43: 227-234

Pezzato, L.E.; Miranda, E.C.; Barros, M.M.; Pinto, L.G.; Furuya, W.M. e Pezzato, A.C. 2002. Digestibilidade aparente de ingredientes pela tilápia do Nilo (Oreochromis niloticus). Rev Bras Zootecn, 31: 1595-1604.
Pezzato, L.E.; Miranda, E.C.; Barros, M.M.; Furuya, W.M. e Pinto, L.G.Q. 2004. Digestibilidade aparente da matéria seca e da proteína bruta e a energia digestível de alguns alimentos alternativos pela tilápia do Nilo (Oreochromis niloticus). Acta Sci. Anim Sci, 26: 329-337.

Rocha, C.M.C.; Resende, E.K.; Routledge, E.A.B. e Lundstedt, L.M. 2013. Avanços na pesquisa e no desenvolvimento da aquicultura brasileira. Pesq Agrope Bras, 48: 4-6.

Rostagno, H.R.; Albino, L.F.T.; Donzele, J.L.; Gomes, P.C.; Oliveira, R.F.; Lopes, D.C.; Ferreira, A.S.; Barreto, S.L.T. e Euclides, R.F. 2011 . Tabelas brasileiras para aves e suínos - Composição de alimentos e exigências nutricionais. $3^{\mathrm{a}}$ ed. UFV. Viçosa, MG. 252 pp.

Santos, A.B. dos. 2006. Sistemas de cultivo. In: Santos, A.B. dos; Stone, L.F.; Vieira, N.R. de A. (Eds.). A cultura do arroz no Brasil. 2.ed. Embrapa Arroz e Feijão. Santo Antônio de Goiás. pp. 451-484.

Santos, E.L.;Winterlew, M.C.; Ludke, M.C.M.M. eBarbosa, J.M. 2008. Digestibilidade de ingredientes alternativos para tilápia-do-Nilo (Oreochromis niloticus): revisão. Rev Bra. Eng Pesca, 3: 135-149.

Santos Jr., A.A.; Ferket, P.R.; Grimes, J.L. and Edens, F.W. 2004. Dietary pentosanase supplementation of diets containing different qualities of wheat on growth performance and metabolizable energy of turkey poults. Int J Poultry Sci, 3: 33-45.

Santos Neta, E.R.; Vaz, R.G.M.V.; Rodrigues, K.F.; Sousa, J.P.L.; Parente. I.P.; Albino, L.F.T.; Siqueira, J.C. e Rosa, F.C.N. 2011 . Níveis de inclusão da torta de babaçu em rações de frangos de corte na fase inicial. Rev Bras de Saúde Prod Anim, 12: 234-243.

Silva, A.G.M.; Borges, I.; Neiva, J.N.; Rodrigues, N. M.; Saliba, E.O.S.; Morais, S.A.; Silva, J.J.; Melo, F.A.; Sousa, T.A.S. e Junior, L.L.M. 2008. Degradabilidade in situ da torta de babaçu - frações fibrosas. V Congresso Nordestino de Produção Animal. Anais... Aracaju-SE. 1 CD-ROM

Silva, J.H.V.; Lima, R.B.; Lacerda, P.B. e Oliveira, A.C. 2014. Digestão e absorção de lipídios. Em: Sakomura, N.K. Nutrição de Não Ruminantes. FUNEP. Jaboticabal. pp. 62-76.

Silva, D.J. eQueiroz. A.C. 2002. Análise de alimentos: métodos químicos e biológicos. 2. ed. UFV. Viçosa, MG. 178 pp.

Siqueira, J.C.; Nascimento, D.C.N.; Vaz, R.G.M.V; Silva, R.F.; Santos Neta, E.R.; Rodrigues, K.F.; Portela, L.B. e Silva, G.S. 2011 . Equações de predição da energia metabolizável da torta de babaçu para frangos de corte. Rev Bras de Saúde Prod Anim, 12: 1016-1025.

Souza, R.A.L. 2004. Piscicultura austentável na Amazônia: Perguntas e respostas. Ministério da Educação. Universidade Federal Rural da Amazônia. Belém, Pará. 158 pp.

Teixeira, E.A.; Saliba, E.O.S.; Euler, A.C.C.; Faria, P.M.C.; Crepaldi, D.V. e Ribeiro, L.P. 2010. Coeficientes de digestibilidade aparente de alimentos energéticos para juvenis de surubim. Rev Bras Zootecn, 39: 1259-1265.

Vieira, A.R.; Rabello, C.B.; Mohaupt, M.C.; Ludke, M.; Dutra Júnior, W.M.; Torres, D.M. e Lopes, J.B. 2007. Efeito de diferentes níveis de inclusão de farelo de arroz em dietas suplementadas com fitase para frangos de corte. Acta Sci. Anim Sci, 29: 267-275. 